\title{
A Survey of Perceived Hindrances to Junior Secondary School Science Teaching
}

\author{
Eminah, J. K. \\ Department of Science Education, University of Education, Winneba
}

\begin{abstract}
This study investigated situations which Junior Secondary Schools (JSS) teachers perceived as hindrances to their teaching functions. A 30-item questionnaire with a 5-point scale was used to collect data from 116 science teachers who taught in private and public schools. The schools were based in rural and urban settings. An examination of the rank ordered hindrances showed that large class sizes, heavy teaching load, lack of funds to purchase materials and inadequate treatment of certain topics in the pupils' textbooks hindered JSS science teachers the most. It was also found that different percentages of teachers perceived each of the situations (the main instrument described) as a serious hindrance. The percentages varied from 68.1 (heavy teaching load) to 14.6 (lack of knowledge in biology). Statistical analysis of the data using the z-test for 2-sample cases showed no significant difference between the hindrances perceived by three compared groups of teachers namely, teachers in rural and urban schools, teachers in private and public schools and teachers who specialised in science and their colleagues who did not. A significant difference was however found between the hindrances perceived by male and female teachers. One major finding of the study is that due to the lack of science teachers in the public schools, teachers who taught other non-science subjects such as Cultural Studies, Life Skills, Social Studies and English Language were assigned to teach science.
\end{abstract}

\section{Introduction}

The need for a purposeful educational system coupled with the general dissatisfaction with the unproductive system of education bequeathed to Ghana by the colonial government resulted in the development of the New Educational Reform Programme. The nationwide implementation of the JSS programme in September, 1987 is part of the reform package for Basic Education. The inclusion of science in the JSS curriculum was meant to meet the needs of society and further education while providing an appropriate science education for the JSS pupils (CRDD, 2001).

The curriculum materials that were developed to ensure the smooth take-off of the JSS science programme included a syllabus, pupils' textbooks and teachers' handbooks. Science kit boxes were also provided to supplement the science teaching and learning materials schools were to buy, collect, improvise or grow for use (MOE, 1986, P. 41).

In an attempt to strengthen the capability of JSS science teachers to cope with certain role expectations under the Reform Programme, intensive training of trainers courses were organised for selected teachers at the Kumasi Technical Institute in January, 1990. These teachers were expected to organise similar courses for JSS science teachers in various Educational Directorates and Zones 
in the country (Nyavor and Oppong, 1990). Prior to this exercise, some teachers had been transferred from the then Middle Schools to Primary Schools. The aim of this exercise was to produce a crop of teachers whose training and experience measured up to the standard expected of JSS teachers.

In spite of the measures the Ghana Education Service (GES) put in place to ensure the success of the JSS science programme many stakeholders complained that its implementation was being rushed. They cited the lack of science teachers, poor infrastructure facilities, low teacher moral and output and the low academic performance of the pupils as problems that should have been tackled head-on.

When the science results of the first batch of JSS pupils at the Basic Education Certificate Examination (BECE) were released in 1990, many science educationists noted that shocking as the results were, they were indicative of serious structural problems with the entire JSS programme.

Commenting on the performance of the first batch of JSS pupils in science at the BECE, the Chief Examiner wrote that the candidates' performance was generally poor and that they were unable to understand the questions (WAEC, 1990, p. 11). Similar comments were made by the Chief Examiner in his 1991 Report. He noted that the majority of the candidates produced answers, which showed that they only had hazy ideas of what was demanded by the questions (WAEC, 1999; p. 39).

Although there appeared to be slight improvements in the candidates' performance in subsequent years, the overall output has not matched expectations. One recurring feature in the Chief Examiner's Reports is the extensive write-up about the candidates' weaknesses as against their strengths. Weaknesses reported on included the candidates' apparent lack of understanding of simple scientific concepts, the unsystematic presentation of calculations, spelling mistakes, wrong labellings and superficial answers. To the BECE Science Chief Examiner, most JSS science teachers taught the subject without practical activities and also seemed to teach only aspects of the syllabus they could conveniently handle.

It is noteworthy that apart from isolated cases of complaints from JSS Science teachers as to the conditions under which they worked, no national attempt had been made to collate the views of the teachers on various aspects of the JSS science programme. Although such a venture is likely to be costly, it is nonetheless a very credible approach to determining whether or not the JSS science programme is on course. There is some evidence that whenever educational authorities failed to devote time and effort to the concerns of teachers, ill feelings developed, resulting in the teachers' refusal to be drawn away from their conventional classroom techniques (Kelly, 1983). Such situations have adverse effects on the intended programme outcomes. If the JSS science programme is to serve the purpose for which it was initiated, then the teachers' views should be tapped to add to the pool of detailed information required to guide implementation. 


\section{Review of Literature}

The JSS science programme has attracted considerable attention from educational researchers. One of the earliest attempts to evaluate certain aspects of the programme was Omari's (1981) study. He focused his attention on science teaching strategies teachers used and found that practical activities were hardly organised by the observed teachers. He, however, stopped short of finding out the science teaching constraints in the Experimental Junior Secondary schools (EXJUSSs) he studied.

In a similar study on the EXJUSSs, Dzebu (1987) focused on only one JSS at Tsito. He found that the school lacked science teaching and learning materials and that the teacher did not utilise the prescribed teaching approaches. A detailed investigation of the local constraints to science teaching was however not carried out. The results of such an investigation would have been instructive as to the steps the designers of the science curriculum of the EXJUSSs could take to solve some of the implementation problems. Tufuor (1989) on his part investigated the implementation of the JSS science programme in Cape Coast District and discovered a number of problems. Notable among the implementation problems were the pupils' weak background in Science and English, the extensive nature of the science syllabus and the lack of furniture and laboratories. Other critical areas of the programme such as the availability of curriculum materials, the adequacy of the contents of the available textual materials, the teachers' knowledge of the subject matter etc. were not investigated.

Yabom (1998) surveyed the available science teaching and learning materials in selected schools in the Tamale Metropolis and found educational provisions in the schools to be very poor. The science teachers were however not asked about problems they perceived as hindrances to their work at school. Consequently, the suggestions Yabom made towards improved teacher performance in the schools centred on science teaching and learning materials only.

A search of the available literature showed that about 20 years ago, Amartey (1981) designed a study to investigate the implementation problems of the Project for Science Integration (PSI). The PSI was meant to replace the then General Science Course and was initially trial-tested in five Secondary Schools (Achimota, Nungua, St. John's Grammar, Ghanatta and Mfantsipim). Amartey generated 27 implementation problems and mailed them to science teachers in schools that were implementing the PSI. The questionnaire items covered five main areas, namely the Methods, Preparation, Departmental and Administrative Problems and Problems in relation to students. He found that the teachers encountered problems in the five areas to varying degrees. Amartey concluded his study by giving suggestions as to how teachers could solve the problems they reported. It was obvious that since the teachers indicated the specific problems they encountered, they were more willing to test the workability of the suggested solutions.

Among the actions the GES had previously taken to solve some of the implementation problems of the JSS science programme was the organisation of courses that focused on the prescribed curriculum materials. The courses 
were ultimately aimed at improving the capabilities of the JSS science teachers. It should however be noted that no needs assessment was conducted before the courses were organised. The tacit assumption was that the GES officials knew what was good for the teachers. Since the teachers are implementers of the JSS science curriculum at the classroom level, their views should be considered before remedial actions are taken. This study was designed to increase the pool of data required to plan appropriate interventions to ensure the achievement of the intended outcomes of the JSS science programme.

\section{Purpose and Research Hypotheses}

The purpose of the study was to determine the extent to which various situations in the schools hindered JSS science teachers from performing their teaching functions effectively.

The following null hypotheses were formulated and tested in the study.

1. There will be no significant difference between the hindrances to JSS science teaching perceived by male and female teachers.

2. There will be no significant difference between the hindrances to JSS science teaching perceived by teachers in rural and urban schools.

3. There will be no significant difference between the hindrances to JSS science teaching perceived by teachers in public and private schools.

4. There will be no significant difference between the hindrances to JSS science teaching perceived by science specialised and non-science specialised teachers.

\section{Research Design}

The survey design was adopted in this study. This was to enable the researcher to sample the views of a wide variety of teachers on the problems they encountered as they implemented the JSS science programme at the classroom level.

\section{Population}

The target population for the study consisted of all JSS science teachers in the country. Due to the researcher's desire to sample the views of a wide crosssection of teachers, Patton's (1990) maximum variety sampling technique was utilised in the selection of the research subjects. Consequently, a countrywide selection was made comprising teachers in Private and Public Schools, teachers in rural and urban schools and male and female teachers. The researcher's intention in selecting a heterogeneous sample was to enable him to determine the commonalities or otherwise of their experiences.

\section{Instrument}

The main instrument used in the study was the Hindrances Assessment Schedule (HAS), which was developed by the researcher and contained 30 items. In order to generate valid items for the HAS, a random selection of JSS science teachers and some experienced educationists were asked to indicate 
their concerns about the JSS science programme. The list was eventually reduced to 30 items.

To ensure the content validity of the instrument the items in it were compared to implementation instructions in the JSS science teacher's handbooks, the science syllabus and official documents on the programme.

Using Pearson's correlation formula a reliability index of 0.912 was calculated for the instrument based on the test re-test procedure. Before being used for the main study the instrument was pilot-tested with 20 JSS science teachers in the Winneba District.

The final version of the instrument was divided into two sections. The first section was designed to collect biographical data. The second section contained 30 items that described situations JSS science teachers were likely to perceive as hindrances to their teaching functions. The teachers were required to indicate the intensity of their responses to each item on a 5 - point scale as A Very Serious Hindrance, B - Serious Hindrance, C - Moderate Hindrance, D Slight Hindrance and E - No Hindrance, Starting from A through to E, the responses were to be scored from 5 to 1 .

\section{Data Collection}

Before the questionnaire was administered the researcher arbitrarily divided the country into three zones - the Southern Zone (Greater Accra, Western and Central Regions), the Middle Zone (Ashanti, Eastern, Volta and Brong Ahafo Regions) and the Northern Zone (Northern, Upper West and Upper East Regions). With the help of student research assistants, 200 questionnaires were distributed in the three zones to various categories of JSS science teachers. One hundred and sixteen (116) usable responses were received over a two-month period. This represented a return rate of $58 \%$. This figure compares favourably with a return rate of $36.7 \%$ for Easter day and Smith (1992) and a $42.6 \%$ return rate for Baird and Rowsey (1989) in similar studies.

\section{Results}

The response rate for each item in the HAS was 100\%. The item mean response score (IMRS) for each item in the HAS was computed from all the responses for each item. The score for "No Hindrance" was excluded from the calculations. The standard deviations were also calculated. The results have been summarised in Table 1. 
Table 1 Rank Ordered Hindrances by Score

\begin{tabular}{|c|c|c|c|c|}
\hline Rank & Hindrance/Situation & Score & Item No. & S.D. \\
\hline 1. & Large class sizes & 4.02 & 28 & 1.19 \\
\hline 2. & Heavy teaching load & 3.97 & 29 & 1.29 \\
\hline 3. & Lack of funds to purchase materials & 3.95 & 2 & 1.15 \\
\hline 4. & Inadequate treatment of some topics & 3.85 & 12 & 1.20 \\
\hline 5. & Teaching interrupted by external activities & 3.83 & 24 & 1.53 \\
\hline 6. & Wide syllabus & 3.76 & 15 & 1.21 \\
\hline 7. & Negative attitude of the pupils & 3.73 & 26 & 1.26 \\
\hline 8. & Insufficient periods & 3.70 & 16 & 1.14 \\
\hline 9. & Lack of in-service training & 3.65 & 20 & 1.31 \\
\hline 10. & Poor academic ability of the pupils & 3.63 & 27 & 1.35 \\
\hline 11. & Some topics are not in the JSS textbooks & 3.62 & 11 & 1.48 \\
\hline 12. & Some BECE questions are irrelevant & 3.56 & 13 & 1.25 \\
\hline 13. & Insufficient equipment and materials & 3.55 & 1 & 1.18 \\
\hline 14. & Teachers' guides not available & 3.50 & 6 & 1.33 \\
\hline 15. & Too many administrative responsibilities & 3.47 & 30 & 1.37 \\
\hline 16. & Insufficient textbooks & 3.44 & 8 & 1.19 \\
\hline 17. & Teaching interrupted by internal activities & 3.35 & 25 & 1.25 \\
\hline 18. & Science syllabus not available & 3.26 & 7 & 1.42 \\
\hline 19. & Lack of knowledge in chemistry & 3.21 & 18 & 1.24 \\
\hline 20. & Lack of knowledge in physics & 3.16 & 19 & 1.24 \\
\hline 21. & Unco-operative attitude of the community & 3.14 & 22 & 1.39 \\
\hline 22. & Improper topic sequencing in syllabus & 3.14 & 14 & 1.32 \\
\hline 23. & Syllabus not always specific & 3.11 & 10 & 1.22 \\
\hline 24. & Difficulty in improvisation of materials & 3.09 & 4 & 1.48 \\
\hline 25. & Unco-operative attitude of headteacher & 3.07 & 23 & 1.35 \\
\hline 26. & The course is full of activities & 3.01 & 9 & 1.30 \\
\hline 27. & Strict rules on the use of materials & 2.99 & 3 & 1.44 \\
\hline 28. & Lack of Knowledge in biology & 2.98 & 17 & 1.16 \\
\hline 29. & Lack of knowledge in the use of some materials & 2.95 & 5 & 1.37 \\
\hline 30. & Unco-operative attitude of colleagues & 2.84 & 21 & 1.48 \\
\hline
\end{tabular}

Overall Mean Score $=3.42$

Overall Sandard Deviation $=1.31$

In order to gain an insight into the proportion of teachers who felt seriously hindered by the situations described by the instrument, the categories of Very Serious Hindrance" and "Serious Hindrance" were collapsed into a single category of "Serious Hindrance". Using this new category, the percentage of teachers who felt seriously hindered by each of the situations described by the items in the main instrument, was calculated. The results have been summarised in Table 2. 
Table 2 Percentage of Teachers Who Felt Seriously Hindered

\begin{tabular}{|c|c|c|}
\hline Rank & Hindrance/Situation & $\%$ of teachers \\
\hline 1. & Heavy teaching load & 68.1 \\
\hline 2. & Inadequate treatment of some topics & 62.1 \\
\hline 3. & Wide syllabus & 61.2 \\
\hline 4. & Lack of funds to purchase materials & 60.3 \\
\hline 5. & Large class sizes & 59.5 \\
\hline 6. & Teaching interrupted by external activities & 53.4 \\
\hline 7. & Insufficient periods & 52.6 \\
\hline 8. & Poor academic ability of the pupils & 52.6 \\
\hline 9. & Some BECE questions are irrelevant & 49.1 \\
\hline 10. & Lack of in-service training & 49.1 \\
\hline 11. & Some topics are not in the JSS textbooks & 48.3 \\
\hline 12. & Insufficient equipment and materials & 48.2 \\
\hline 13. & Too many administrative responsibilities & 41.4 \\
\hline 14. & Teachers' guides not available & 38.8 \\
\hline 15. & Teaching interrupted by internal activities & 34.5 \\
\hline 16. & Insufficient textbooks & 32.8 \\
\hline 17. & Negative attitude of the pupils & 31.0 \\
\hline 18. & Unco-operative attitude of the community & 29.3 \\
\hline 19. & Difficulty in improvisation & 28.4 \\
\hline 20. & Syllabus not always specific & 27.6 \\
\hline 21. & Improper topic sequencing in syllabus & 23.3 \\
\hline 22. & Unco-operative headteacher & 20.7 \\
\hline 23. & The course is full of activities & 19.0 \\
\hline 24. & Lack of knowledge in chemistry & 19.0 \\
\hline 25. & Lack of knowledge in physics & 19.0 \\
\hline 26. & Strict rules on the use of materials & 18.1 \\
\hline 27. & Science syllabus not available & 18.1 \\
\hline 28. & Unco-operative colleagues & 16.3 \\
\hline 29. & Lack of knowledge in the use of some materials & 14.6 \\
\hline 30. & Lack of knowledge in biology & 14.6 \\
\hline
\end{tabular}

Average $\%=36.0$

The classification of the teachers into male/female, trained/untrained, urban/rural etc. based on a total of 116 teachers is shown in Table 3 . The criteria used for the classification were the sex of the teachers, the setting of the schools, the professional status of the teachers, the type of schools and the subject specialisation of the teachers. 
Table 3 Classification of the teachers

\begin{tabular}{cccccccccc}
\hline \multicolumn{2}{c}{ Sex } & \multicolumn{2}{c}{ School Setting } & \multicolumn{2}{c}{ School type } & \multicolumn{2}{c}{ Status } & \multicolumn{2}{c}{ Specialisation } \\
\hline \multirow{2}{*}{ Female } & Male & Urban & Rural & Public & Private & Trained & Untrained & Science & $\begin{array}{c}\text { Non- } \\
\text { science }\end{array}$ \\
22 & 94 & 58 & 58 & 99 & 17 & 99 & 17 & 92 & 24 \\
\hline
\end{tabular}

It was found that there was a disproportionate number of untrained teachers in the private schools compared to those in the public schools. The qualifications of the teachers in the public land private schools are shown in Table 4.

Table 4: Qualification of the Teachers

\begin{tabular}{lcc}
\hline \multirow{2}{*}{ Qualification } & \multicolumn{2}{c}{ Number of Teachers } \\
& Public Schools & Private Schools \\
\hline "O" Level & 1 & - \\
“A” Level & 6 & 8 \\
Cert "A" (4-Year) & 1 & - \\
Cert “A" (2-Year Post-Sec) & 7 & - \\
Cert “A” (3-Year Post-Sec) & 70 & 7 \\
Specialist & 7 & - \\
Diploma & 7 & 1 \\
B.A./B.Sc. & - & $1 *$ \\
Total & 99 & 17 \\
\hline
\end{tabular}

\section{Hypotheses Testing}

Statistical analysis of the data was done using four parametric tests. Because of the large number (116) of research subjects involved, the Z-test for 2-sample cases was used to test the significances between the hindrances perceived by different groups of teachers. The groups considered were the urban and rural school teachers, male and female teachers, trained and untrained teachers, private schools and public school teachers and non-science specialised and science specialised teachers.

The only difference that was found to be statistically significant was that between the hindrances perceived by male and female teachers. The results have been summarised in Table 5 . 
Table 5: Summary Z-Test Results

\begin{tabular}{lcccc}
\hline \multicolumn{1}{c}{ Groups Compared } & $\begin{array}{c}\text { Numbers } \\
\text { of } \\
\text { Teachers }\end{array}$ & Mean & S.D. & Z-Value \\
\hline Rural school teachers & 58 & 2.818 & 0.609 & $1.479^{*}$ \\
Urban school teachers & 58 & 2.745 & 0.605 & \\
Female teachers & 22 & 2.822 & 0.588 & $2.701^{* *}$ \\
Male teachers & 94 & 3.20 & 0.618 & \\
Private school teachers & 17 & 2.792 & 0.690 & $0.242^{*}$ \\
Public school teachers & 99 & 2.835 & 0.598 & \\
Science specialised teachers & 92 & 2.765 & 0.707 & $0.390^{*}$ \\
Non-science specialised teachers & 24 & 2.831 & 0.611 & \\
\hline$\quad$ *Not significant Z-test $=1.96 \mathrm{P}<0.05$ & & & \\
$\quad$ **Significant & & & &
\end{tabular}

\section{Discussion}

The major purpose of this study was to determine the extent to which various situations in the schools hindered JSS science teachers in their teaching functions. An examination of the ranked hindrances in Table 1 shows that on the whole, the teachers were most hindered by school-specific situations (large class sizes, heavy teaching loads and the lack of funds to purchase materials). The inadequate treatment of some topics in the JSS textbooks, the interruption of teaching by external activities and the extensive nature of the JSS science syllabus also hindered the teachers to an appreciable extent. Since these three situations originated from outside the school, they affected all the teachers and were thus likely to have adverse effects on the performance of the teachers as a whole. While headteachers and teachers could take steps (at the local level) to solve school-specific problems such as heavy teaching loads, there appeared to be very little they could do to solve problems connected, for example, with inappropriate curriculum materials.

One other significant finding was the lack of in-service training courses which $49.1 \%$ of the teachers reported as a serious hindrance. This area is critical to the teachers' professional competence since they are to keep abreast with current science teaching and learning approaches and issues. Indeed a high proportion of the situations the JSS science teacher perceived as serious hindrances could have been rectified had regular in-service trainings been organised for the teachers (Becker \& De Guire, 1983).

It was found that even when in-service training programmes were organised science teachers from the private schools were excluded. This practice is a serious set-back for science education in the country in that a high proportion of the JSS science teachers in the private schools are untrained. In the present study, $9(53 \%)$ of the 17 JSS science teachers in the private schools were untrained. One of the untrained teachers held a B.A. (Linguistics) degree while 
the rest were "A" Level holders. As Cobbinah (1996) noted, untrained teachers added to the learning problems of the JSS pupils instead of solving them.

It appears that since the Ministry of Education (MOE) supplied science kit boxes to the schools at the inception of the JSS science programme, no serious attempt has been made to augment the teaching and learning materials in the schools. Many teachers thus felt hindered by the lack of teaching and learning materials and were sometimes forced to adopt literary approaches to science teaching. Abdulahi (1982) has noted that some concepts in science can only be learnt properly through practical activities. In the absence of teaching and learning materials, JSS science teachers automatically revert to traditional didactic teaching (Kelly, 1983) thus making it difficult for the aims of the JSS science programme to be achieved.

The data in Table 1 indicate that the responding teachers found the teaching of chemistry topics in the JSS science syllabus more difficult compared to physics and biology topics. This adds support to the statement by the BECE Science Chief Examiner that the JSS pupils appeared to have problems with questions based on chemistry topics (WAEC, 1992, p. 55).

Since the teachers lacked knowledge in chemistry, they were not likely to treat chemistry topics in the JSS science syllabus adequately. The pupils thus suffered from cognitive deficiencies with respect to chemistry and consequently performed poorly on tests based on chemistry topics. Since the inadequate knowledge of the teachers could have originated from the training colleges (haggis, 1977), the science curriculum of the training colleges ought to be examined and revised if necessary.

A review of the data showed that teachers in both private and public schools were comparable in their perception of "heavy teaching load" as a hindrance to their teaching functions. It is likely that the desire of the proprietors of private schools to maximise profits caused them to increase the workload of the science teachers. As was noted earlier, the increased workload of the public school teachers might be due to the lack of teachers with the appropriate qualifications.

The fact that no significant differences were found in the hindrances perceived by 3 out of the 4 groups of teachers compared shows that the problems JSS science teachers encountered in the field cut across different categories of teachers in the country. This in effect implies that apart from the school specific problems, JSS science teachers faced similar problems at school. This finding agrees with that of Oladimeji (1978) in Bajah (1983). It will thus not be difficult for the Ministry of Education to initiate interventions to solve the problems of JSS science teachers. The most important element in any proposed remedial measure is the promptness with which the activities are initiated. (Conley, 1991). Prompt action should therefore be taken to improve science teaching and learning at the JSS level in order not to cause the teachers to leave the profession out of frustration. 


\section{Recommendations}

To minimise the frustrations of JSS science teachers in the performance of their teaching functions the following measure are recommended:

1. The Curriculum Research and Development Division (CRDD) unit of the GES should be strengthened to address the concerns of JSS science teachers with respect to the content of the science curriculum materials. This apart, the activities of the CRDD should be decentralised to make the personnel more accessible to JSS science teachers.

2. Personnel at the various science resource centres should be trained to offer support services to JSS science teachers in the districts. The focus of the services could be the organisation of practical activities and the utilisation of innovative science teaching approaches.

3. The GES should encourage JSS science teachers to patronise the activities of the JSS panel of the Ghana Association of Science Teachers (GAST). Regular interactions with their colleagues is likely to expose the teachers to workable strategies they could also adopt to solve some of their school-specific problems.

4. To avoid literary approaches to science teaching and learning only science specialised teachers should be assigned to teach JSS science. Where only non-specialised teachers are available they should be made to undergo complementary training to make up for gaps in their knowledge and skill.

\section{Conclusion}

The findings of this study indicate that JSS science teachers are considerably hindered by both school-specific and countrywide situations. Customised approaches (Becher and De Guire, 1983) could be used to solve the schoolspecific problems based on the unique characteristics of the schools. On the other hand, highly intensive broad-based remediation interventions (Conley, 1991) could be used to solve the countrywide problems encountered by JSS science teachers. A good way to solve teachers' problems is by asking the teachers themselves (Baird, Easterday, Rowsey, \& Smith 1993). Since the number of teachers who participated in this study is small, other researchers could replicate the study with larger samples to ensure that a representative number of JSS science teachers express their concerns. These concerns can be used as credible data for future intervention activities to improve the JSS science programme.

\section{References}

Abdulahi, A. (1982). Science Teaching in Nigeria. Illorin. Atoto Press Lted.

Amartey, K. (1981). Report on Investigation of Problems in Implementation of PSI. Journal of Ghana Association of Science Teachers, 1981-82, 411. 
Baird, W. E., Easterday, K., Rowsey, R. E. \& Smith, T. (1993). A Comparison of Alabama Secondary Science and Mathematics Teachers: Demographics and Perceived Needs. School Science and Mathematics 93(4), 175-182.

Baird, W. E \& Rowsey, R. E. (1989). _A Survey of Secondary Science Teacher Needs. School Science and Mathematics 89, 272-284.

Bajah, T. (1983). Teaching Integrated Science Creatively. Ibadan: Ibadan University Press.

Beckner, W. \& De Guire, D. (1983). Needs in Smaller Schools of the United States: A Study. La Gruices N. M.: New Mexico Centre for Rural Education.

Cobbinah, J. E. (1996). The Effects of Science Teaching by Untrained Science Teachers in Selected Junior Secondary Schools. Unpublished Diploma Long Essay, UCEW.

Conley, D. T. (1991). Eight Steps to Improved Teacher Remediation. Bulletin of the National Association of Secondary School Principals 75 (536), 2640.

Curriculum Research and Development Division (2001). Teaching Syllabus for Science (JSS). Accra: Ghana.

Dzebu, C. K. (1987). The Problems in the teaching of science in Junior Secondary Schools in Ghana With Particular Reference to Tsito JSS. Unpublished Diploma Long Essay.

Easterday, K. E. \& Smith, Y. (1992). A Survey of Mathematics Teacher Needs. School Science and Mathematics 92 (4), 213-219.

Haggis, S. M. (1997). Trends in the Teaching of Integrated Science Worldwide. Journal of the Ghana Association of Science Teachers 16 (2), 22-31.

Kelly, A. V. (1983). The Curriculum: Theory and Practice (2nd Ed.). London: Harper \& Row.

Ministry of Education (1986). Science Teacher's Handbook for JSS 1. Accra: Ghana.

Nyavor, C. B. \& Oppong, I. K. (1990). Teaching Science at the JSS Level. Paper presented at the Training of Trainers Course at the Kumasi Technical Institute.

Omari, K. D. (1981). Utilization of the JSS Science Curriculum for Ghana. Unpublished Masters Thesis, UCC, Cape Coast.

Patton, M. Q. (1990). Qualitative Evaluation and Research Methods (2nd Ed.) Moubury Park, CA: Sage.

Tufuor, J. K. (1989). Implementation of the JSS Science Programme in Cape Coast District: A Case Study. Journal of the Ghana Association of Science Teachers, June, 1989. 28-46.

West African Examinations Council (1990). BECE Chief Examiners' Report. Accra, Ghana. 
West African Examinations Council (1991). BECE Chief Examiners' Report. Accra, Ghana.

West African Examinations Council (1992). BECE Chief Examiners' Report. Accra, Ghana.

Yabom, Y. V. (1998). A Survey of Science Teaching Materials in Selected Junior Secondary Schools in Tamale. Unpublished Diploma Long Essays. 